\title{
La Universidad Veracruzana celebró Taller de Responsabilidad Social Universitaria
}

Del 15 al 19 de octubre de 2018, la Universidad Veracruzana recibió al Dr. Maximiliano Alonso miembro del Comité Ejecutivo del Observatorio Regional de Responsabilidad Social para América Latina y el Caribe (ORSALC). En su primera visita a la ciudad de Xalapa, el Dr. Maximiliano Alonso quien además es Fundador y Director de CONEXX Europa, organización con sede en Bruselas, Bélgica, impartió el taller "Universidad Socialmente Responsable: Orientaciones para el cambio sistémico" donde reflexionó con académicas, académicos y funcionarios de esta casa de estudios en torno al concepto de universidad, su posición en la sociedad y su compromiso con la transformación de la realidad.

A lo largo de una semana, en el salón Audiovisual de la Facultad de Arquitectura en Xalapa, se trabajó en el diseño de proyectos y acciones tendientes a la RSU para su implementación en la Universidad Veracruzana. Debido a su importancia el taller fue transmitido a las Regiones de Veracruz, Orizaba, Coatzacoalcos y Poza Rica, desde donde tuvieron la oportunidad de interactuar con el ponente y con las personas asistentes en Xalapa para intercambiar opiniones y retroalimentar los planteamientos de sus proyectos.

Gracias a la tecnología, se contó con la intervención de la Dra. Rosa Terradellas Piferrer Directora de la Cátedra RSU de la Universidad de Girona en Cataluña España, de la Dra, Andrea Riccio de la Universidad de la Sapienza Roma y de la Dra. Silvana Mandolessi de la Universidad KU Leuven, Bélgica, asimismo con Erik Ruiz Martin y Gianmarco Garramone Gestores de Proyectos de CONEXX Europa, quienes se comunicaron desde la sede de la organización en Bruselas para ahondar en el tema y enriquecer la discusión.

La participación de representantes de áreas estratégicas de la Universidad Veracruzana en este taller busca garantizar el seguimiento e implementación de nuevas acciones encaminadas a

la RSU desde esta Universidad.

Pueden consultar https://www.uv.mx/cuo/
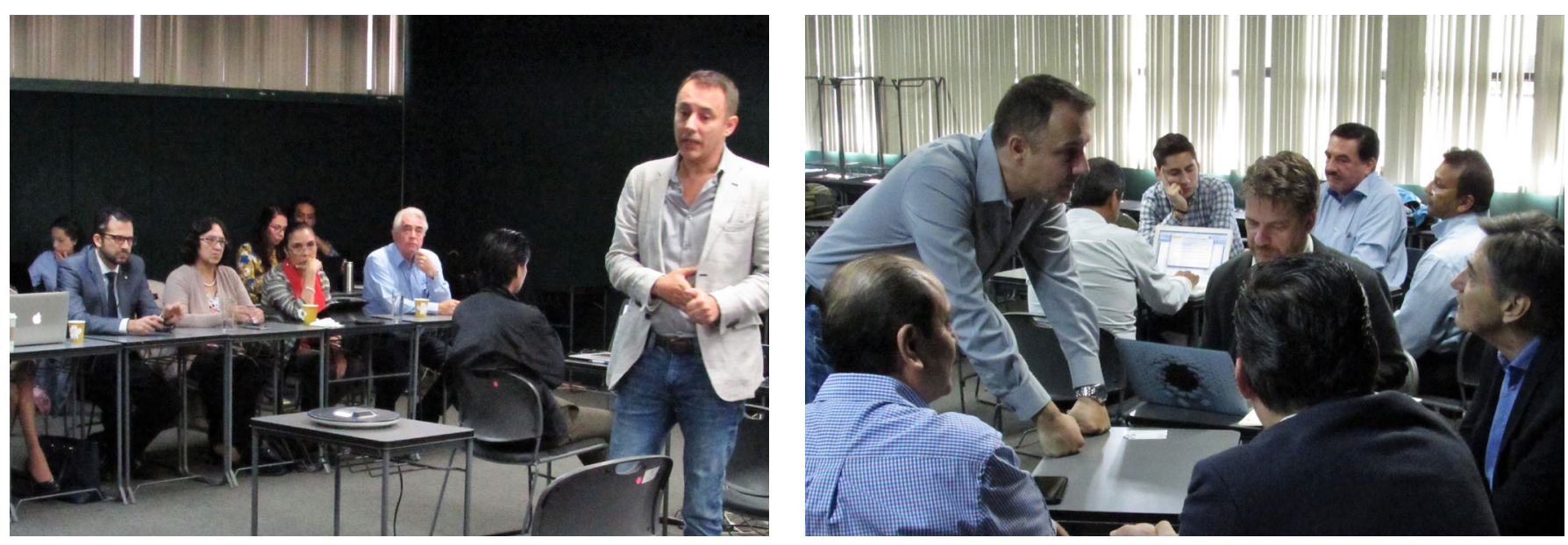